\title{
Prevention of Postoperative Nausea and Vomiting in Elective Hysterectomy: A Prospective, Randomized, Placebo Controlled Outcomes Trial of Aprepitant NK-1-Receptor Antagonist
}

\author{
Jaime B. Long1*, Luisa Galdi', Joseph G. Hentz ${ }^{2}$, John B. Leslie, Paul M. Magtibay4, \\ Rosanne M. C. Kho ${ }^{4}$, Jeffrey L. Cornella ${ }^{4}$, Javier F. Magrina ${ }^{4}$ \\ ${ }^{1}$ Department of Obstetrics and Gynecology at Reading Health System, West Reading, USA \\ ${ }^{2}$ Department of Biostatistics, Mayo Clinic, Scottsdale, USA \\ ${ }^{3}$ Department of Anesthesiology, Mayo Clinic, Scottsdale, USA \\ ${ }^{4}$ Department of Gynecologic Surgery, Mayo Clinic, Scottsdale, USA \\ Email: "Jaime.Long@readinghealth.org
}

Received 9 October 2014; revised 10 November 2014; accepted 28 November 2014

Copyright (C) 2014 by authors and Scientific Research Publishing Inc.

This work is licensed under the Creative Commons Attribution International License (CC BY). http://creativecommons.org/licenses/by/4.0/

(c) (i) Open Access

\begin{abstract}
Objectives: Current prophylactic interventions fail to completely eliminate postoperative nausea and vomiting (PONV) for a substantial number of patients. A new antiemetic (aprepitant) has been effective in preventing chemotherapy induced nausea and vomiting (CINV). We hypothesized that adding aprepitant to our current prophylactic regimen of dexamethasone and ondansetron would reduce the incidence of PONV in our elective hysterectomy population. Methods: 256 patients undergoing elective hysterectomy were enrolled in this prospective, randomized, double blinded, placebo controlled trial. Subjects received either oral aprepitant $40 \mathrm{mg}$ or oral placebo 30 minutes prior to induction of standardized anesthesia. The primary outcome was vomiting within the first 24 hours after surgery. Postoperative nausea, vomiting, and use of rescue antiemetics were documented over a $24 \mathrm{~h}$ period. Additionally, adverse events, hospitalization days, and readmissions for PONV were compared. Results: There was a trend towards reduction of postoperative nausea and vomiting in the aprepitant group. Nausea and vomiting were noted for $24 \%$ and $17 \%$ of women in the aprepitant group versus $38 \%$ and $29 \%$ of women in the Placebo group, respectively. Supplemental antiemetic medication was used by $42 \%$ of women in the aprepitant group versus $60 \%$ of women in the Placebo group. No adverse events were substantially more common in the
\end{abstract}

*Corresponding author.

How to cite this paper: Long, J.B., et al. (2014) Prevention of Postoperative Nausea and Vomiting in Elective Hysterectomy: A Prospective, Randomized, Placebo Controlled Outcomes Trial of Aprepitant NK-1-Receptor Antagonist. Open Journal of Anesthesiology, 4, 301-307. http://dx.doi.org/10.4236/ojanes.2014.412043 
aprepitant group than the Placebo group. Conclusions: Preemptive use of aprepitant prior to elective hysterectomy may reduce the incidence of PONV and diminish the need for rescue antiemetics postoperatively. Further studies with larger power are needed to confirm the trends observed in this study.

\section{Keywords}

\section{Hysterectomy, Postoperative Nausea and Vomiting, Aprepitant}

\section{Introduction}

Postoperative nausea and vomiting (PONV) is defined as nausea or vomiting within 24 hours of surgery. It is the most frequent side effect after anesthesia, occurring in approximately $30 \%$ of unselected patients, and can be increased up to $70 \%$ in certain populations and procedures [1]. Intraabdominal surgery, gynecologic surgery, and prolonged duration of anesthesia are risk factors for experiencing PONV. Moreover, the incidence in females is estimated to be three times greater than males [2]. Despite screening and routine prophylaxis of patients at high risk for PONV, current prophylactic interventions fail to completely eliminate PONV for a substantial number of patients, leading to dehydration, electrolyte imbalance, prolonged hospitalizations, multiple doses of rescue medications, and readmissions to the hospital [3].

The pathophysiology of PONV is complex and multifactorial with several different receptors and stimuli contributing to the process. At least 7 neurotransmitter types have been identified in the mechanism of PONV, including serotonin, dopamine, muscarine, acetylcholine, neurokinin-1, histamine, and opioids [2]. The role of "substance P" in eliciting PONV is of particular interest as it is the most abundant neurokinin found in the central and peripheral nervous system [4]. The release of substance P is thought to be triggered by input from both the gut and the area postrema of the brain. The substrate then activates the neurokinin-1 (NK-1) receptors in the nucleus tractus solitaries, which in turn transmits the signal for a vomiting response [5].

Aprepitant (Emend) is the first neurokin-1-receptor antagonist in a new class of antiemetics, which has already demonstrated powerful additive effects when combined with dexamethasone and a 5-HT3 to prevent both acute and delayed chemotherapy-induced nausea and vomiting (CINV) [4]-[12]. Early studies have also suggested that it may be useful in the prevention of postoperative nausea and vomiting (PONV) [13]. We hypothesized that adding aprepitant to the current prophylactic measures of dexamethasone and ondansetron would reduce the incidence of PONV in our elective hysterectomy population.

\section{Materials and Methods}

This study was designed as a single-center prospective, randomized, double blind, placebo controlled trial comparing aprepitant to placebo in eligible patients. The patients recruited for this study consisted of adult gynecologic patients undergoing inpatient elective hysterectomy surgery. Eligible participants signed written informed consents and met all the following criteria: female greater than 18 years old, fluent in English language, scheduled for inpatient elective hysterectomy requiring general anesthesia of at least 30 minutes duration, and classified as Class I, II or III according to the American Society of Anesthesiologists (ASA) physical status classification system. Patient did not qualify for the study if they had a positive urine or serum pregnancy test done within seven days of study was positive; were currently breastfeeding; were undergoing concomitant bowel surgery other than appendectomy; had a known hypersensitivity to the study medication (aprepitant) or to any of the antiemetic rescue medications (odansetron, hydroxyzine, or promethazine), had a level of preoperative nausea of $>4$ on the Visual Rating Scale (VRS); had severe hepatic insufficiency as determined by a Child-Pugh score > 9 or any condition which impaired the patient's ability to complete study assessments; were currenting taking Rifampin, cabemazepine, and pheyntoin and other drugs which strongly induce CYP3A4 activity; had used antiemetics within 12 hours prior to surgery; had a history of clinically significant abuse of substances (alcohol, illicit, or prescribed medications) such that the patient was unable to provide informed consent or reliably complete any of the study assessments; or had a history of a psychiatric illness that may impair the patient's ability to provide informed consent or complete any of the study assessments. 
Patients undergoing elective hysterectomy were enrolled at the time of their preoperative visit. Participants were allocated to aprepitant or placebo treatment arms at random in a one-to-one ratio. A computerized random number generator was used to create the treatment allocation schedule, which was stored by the pharmacy.

Subjects received either oral aprepitant $40 \mathrm{mg}$ or oral placebo approximately 30 minutes prior to induction of standardized anesthesia (which included dexamethasone and ondansetron, propofol induction, and inhalation maintenance with opioids as needed for pain control). The primary outcome measure was whether vomiting occurred within the first 24 hours after surgery. Postoperative nausea (assessed with a Visual Rating Scale (VRS)), vomiting, and use of rescue antiemetic therapy were documented over a $24 \mathrm{~h}$ period. Additionally, adverse events, hospitalization days, and readmissions for PONV were compared.

The incidence of vomiting in the aprepitant group was compared to the Placebo group. Statistical significance was calculated using the Pearson chi-square test. A sample of 400 women was planned. A sample of 200 patients per group would have $80 \%$ power $(\alpha=0.05)$ if the incidence of vomiting were $10 \%$ for aprepitant treatment versus $20 \%$ for placebo treatment. The incidence of other outcome events was compared by using the Pearson chi-square test or Fisher exact test.

Anesthesia regimens were standardized for all patients participating in this study as follows:

- Anesthesia Premedication: Midazolam 1 - 4 mg IV as needed, antibiotics per Surgical Care Improvement Project (SCIP) guidelines

- Anesthesia Induction: Dexamethasone 8mg IV, Propofol 1 - $2 \mathrm{mg} / \mathrm{kg}$ IV and fentanyl 1 - $2 \mu \mathrm{g} / \mathrm{kg}$ IV for anesthesia induction, Rocuronium 0.5 - $1 \mathrm{mg} / \mathrm{kg}$ for neuromuscular relaxation

- Anesthesia Maintenance: Sevoflurane $1 \%$ - 4\% inspired in combination with air $(1 \mathrm{~L} / \mathrm{min})$ and oxygen $(1$ $\mathrm{L} / \mathrm{min}$ ) and supplemental opioid of fentanyl $1-5 \mu \mathrm{g} / \mathrm{kg}$ IV or morphine $0.1-0.2 \mathrm{mg} / \mathrm{kg}$ IV or hydromorphone $0.02-0.05 \mathrm{mg} / \mathrm{kg}$ as needed.

- Anesthesia Emergence: Ondansetron $4 \mathrm{mg}$ IV within 15 minutes of end of surgery, residual neuromuscular blockade reversed with glycopyrrolate, $3 \mu \mathrm{g} / \mathrm{kg}$ IV, and neostigmine $30 \mu \mathrm{g} / \mathrm{kg} \mathrm{IV}$, Sevoflurane discontinued and the inspired oxygen flow increased to $5 \mathrm{~L} / \mathrm{min}$ until patient awake and endotracheal tube removed.

- The airway was secured by either endotracheal intubation or laryngeal mask airway as deemed necessary by the anesthesia team.

Postoperative nausea control regimens were standardized in a step-wise fashion for all patients participating in this study as follows:

1) Ondansetron 4 mg IV PRN every 6 hours;

2) Promethazine $12.5 \mathrm{mg}$ IV/PO/IM/PR PRN every 6 hours;

3) Hydroxyzine $25 \mathrm{mg}$ IV/PO/IM PRN every 12 hours.

Rescue antiemetics required in the PACU were at the discretion of the anesthesiologist caring for the patient. Postoperative pain control methods were at the discretion of the provider.

\section{Results}

Enrollment began July 2007 and was stopped October 2011 due to slow accrual. There were 125 women allocated to receive aprepitant treatment and 131 allocated to receive placebo treatment (Table 1). The number of women who were excluded during screening and the number who declined consent to participate were not recorded. Six women allocated to aprepitant and 9 women allocated to placebo were excluded during surgery. The primary outcome measure was recorded for 35 women in the Aprepitant group and 59 women in the Placebo group. Adverse events within 6 weeks after surgery were recorded for 34 women in the Aprepitant group and 37 women in the Placebo group.

Baseline characteristics are summarized in Table 2. Mean age was 56 years, and the mean duration of surgery was 160 minutes.

Vomiting within 24 hours after surgery was noted for $17 \%$ of women in the Aprepitant group versus $29 \%$ of women in the Placebo group (Table 3). Supplemental antinausea medication was used by $42 \%$ of women in the Aprepitant group versus $60 \%$ of women in the Placebo group. No adverse events were substantially more common in the Aprepitant group than the Placebo group (Table 4). Outcome data were missing for a large proportion of the sample. In addition, the proportion of missing data was higher in the Aprepitant group than in the Placebo group. The results, therefore, might have been influenced by selection bias. 
Table 1. Participant flow diagram.

\begin{tabular}{ccc}
\hline & \multicolumn{2}{c}{ Randomized } \\
\hline & Aprepitant & Placebo \\
\hline Allocated to Intervention & 125 & 131 \\
Excluded During Surgery & 6 & 9 \\
Primary Outcome Measure Not Recorded & 84 & 63 \\
Analyzed in Primary Efficacy Analysis & 35 & 59 \\
\hline
\end{tabular}

Table 2. Baseline.

\begin{tabular}{ccc}
\hline & Aprepitant & Placebo \\
\hline Age (y); mean (SD), N & 60 (12), 50 & $53(12), 70$ \\
Nausea ( - 10); mean (SD), N & $0.10(0.44), 40$ & $0.16(0.56), 57$ \\
Surgery Duration (minutes); mean (SD), N & $153(64), 48$ & $159(81), 69$ \\
Type of Surgery & & $9 / 69(13 \%)$ \\
Laparoscopic & $3 / 49(6 \%)$ & $5 / 69(7 \%)$ \\
Open & $6 / 49(12 \%)$ & $27 / 69(39 \%)$ \\
Robotic & $23 / 49(47 \%)$ & $28 / 69(41 \%)$ \\
\hline
\end{tabular}

Table 3. Outcomes.

\begin{tabular}{|c|c|c|c|c|c|}
\hline & Aprepitant & Placebo & $\Delta$ & $95 \%$ CI & $\boldsymbol{P}$ \\
\hline \multicolumn{6}{|l|}{ Vomiting } \\
\hline Within 24 Hours $^{\mathrm{a}}$ & 6/35 (17\%) & 17/59 (29\%) & -0.12 & -0.29 to 0.05 & 0.20 \\
\hline OR Emergence & $0 / 44(0 \%)$ & 0/67 (0\%) & 0.00 & -0.06 to 0.08 & $>0.99$ \\
\hline PACU & 3/42 (7\%) & 7/60 (12\%) & -0.05 & -0.17 to 0.09 & 0.52 \\
\hline 24 Hours & 4/42 (10\%) & 13/63 (21\%) & -0.11 & -0.24 to 0.02 & 0.13 \\
\hline \multicolumn{6}{|l|}{ Medication } \\
\hline PACU to 24 Hours & $21 / 50(42 \%)$ & $42 / 70(60 \%)$ & -0.18 & -0.36 to 0.00 & 0.05 \\
\hline OR & $44 / 50$ (88\%) & $63 / 70(90 \%)$ & -0.02 & -0.13 to 0.09 & 0.73 \\
\hline PACU & $13 / 50(26 \%)$ & $24 / 70$ (34\%) & -0.08 & -0.25 to 0.08 & 0.33 \\
\hline 24 Hours & $13 / 50(26 \%)$ & $24 / 70$ (34\%) & -0.08 & -0.25 to 0.08 & 0.33 \\
\hline \multicolumn{6}{|l|}{ Nausea } \\
\hline OR Emergence & 0/43 (0\%) & 0/67 (0\%) & 0.00 & -0.06 to 0.08 & $>0.99$ \\
\hline 24 Hours & $10 / 42(24 \%)$ & 24/63 (38\%) & -0.14 & -0.32 to 0.03 & 0.12 \\
\hline
\end{tabular}

${ }^{\mathrm{a}}$ Primary outcome measure.

\section{Discussion}

Despite advances in the treatment and prevention of PONV, this problem continues to affect timely surgical recovery for many patients. PONV not only diminishes quality of life for patients, but also increases health care 
Table 4. Adverse events within 6 weeks after surgery.

\begin{tabular}{|c|c|c|c|c|c|}
\hline & Aprepitant & Placebo & $\Delta$ & $95 \% \mathrm{CI}$ & $\boldsymbol{P}$ \\
\hline $\mathrm{N}$ & 34 & 37 & & & \\
\hline Any Adverse Event & $17 / 34(50 \%)$ & $19 / 37(51 \%)$ & -0.01 & -0.25 to 0.22 & 0.91 \\
\hline Any Serious Adverse Event ${ }^{\mathrm{a}}$ & 3/34 (9\%) & $2 / 37(5 \%)$ & 0.03 & -0.09 to 0.15 & 0.57 \\
\hline Wound Dehiscence & $2(6 \%)$ & $0(0 \%)$ & 0.06 & -0.04 to 0.20 & 0.23 \\
\hline Paresthesia & $2(6 \%)$ & $0(0 \%)$ & 0.06 & -0.04 to 0.20 & 0.23 \\
\hline Wound Infection & $7(21 \%)$ & $6(16 \%)$ & 0.04 & -0.14 to 0.22 & 0.63 \\
\hline Blood Clot in Leg & $1(3 \%)$ & $0(0 \%)$ & 0.03 & -0.07 to 0.15 & 0.48 \\
\hline Bradycardia & $1(3 \%)$ & $0(0 \%)$ & 0.03 & -0.07 to 0.15 & 0.48 \\
\hline Chylous Ascites & $1(3 \%)$ & $0(0 \%)$ & 0.03 & -0.07 to 0.15 & 0.48 \\
\hline Hospital-Aquired Pneumonia & $1(3 \%)$ & $0(0 \%)$ & 0.03 & -0.07 to 0.15 & 0.48 \\
\hline Hot Flashes & $2(6 \%)$ & $1(3 \%)$ & 0.03 & -0.09 to 0.17 & 0.60 \\
\hline Nausea $^{\mathrm{b}}$ & $2(6 \%)$ & $1(3 \%)$ & 0.03 & -0.09 to 0.17 & 0.60 \\
\hline Stomach Pain & $1(3 \%)$ & $0(0 \%)$ & 0.03 & -0.07 to 0.15 & 0.48 \\
\hline Valley Fever & $1(3 \%)$ & $0(0 \%)$ & 0.03 & -0.07 to 0.15 & 0.48 \\
\hline Anemia & $1(3 \%)$ & $1(3 \%)$ & 0.00 & -0.12 to 0.13 & $>0.99$ \\
\hline Back Pain & $1(3 \%)$ & $1(3 \%)$ & 0.00 & -0.12 to 0.13 & $>0.99$ \\
\hline Clostridium Difficile & $1(3 \%)$ & $1(3 \%)$ & 0.00 & -0.12 to 0.13 & $>0.99$ \\
\hline Constipation & $2(6 \%)$ & $2(5 \%)$ & 0.00 & -0.13 to 0.15 & $>0.99$ \\
\hline Gas Pain & $1(3 \%)$ & $1(3 \%)$ & 0.00 & -0.12 to 0.13 & $>0.99$ \\
\hline Urinary Retention & $1(3 \%)$ & $1(3 \%)$ & 0.00 & -0.12 to 0.13 & $>0.99$ \\
\hline Headache & $1(3 \%)$ & $2(5 \%)$ & -0.02 & -0.16 to 0.10 & $>0.99$ \\
\hline Abdominal Pain & $0(0 \%)$ & $1(3 \%)$ & -0.03 & -0.15 to 0.08 & $>0.99$ \\
\hline Fatigue & $0(0 \%)$ & $1(3 \%)$ & -0.03 & -0.15 to 0.08 & $>0.99$ \\
\hline Fever & $0(0 \%)$ & $1(3 \%)$ & -0.03 & -0.15 to 0.08 & $>0.99$ \\
\hline Intestinal Perforation & $0(0 \%)$ & $1(3 \%)$ & -0.03 & -0.15 to 0.08 & $>0.99$ \\
\hline Itching & $0(0 \%)$ & $1(3 \%)$ & -0.03 & -0.15 to 0.08 & $>0.99$ \\
\hline Joint Pain in Shoulder & $0(0 \%)$ & $1(3 \%)$ & -0.03 & -0.15 to 0.08 & $>0.99$ \\
\hline Oral Thrush & $0(0 \%)$ & $1(3 \%)$ & -0.03 & -0.15 to 0.08 & $>0.99$ \\
\hline Vomiting $^{\mathrm{b}}$ & $0(0 \%)$ & $1(3 \%)$ & -0.03 & -0.15 to 0.08 & $>0.99$ \\
\hline Wound Seroma & $0(0 \%)$ & $1(3 \%)$ & -0.03 & -0.15 to 0.08 & $>0.99$ \\
\hline Diarrhea & $0(0 \%)$ & $2(5 \%)$ & -0.05 & -0.18 to 0.05 & 0.49 \\
\hline Rash & $0(0 \%)$ & $2(5 \%)$ & -0.05 & -0.18 to 0.05 & 0.49 \\
\hline Urinary Tract Infection & $1(3 \%)$ & $6(16 \%)$ & -0.13 & -0.29 to 0.01 & 0.11 \\
\hline
\end{tabular}

${ }^{\mathrm{a}}$ The serious adverse events were anemia, blood clot in leg, hospital-acquired pneumonia, intestinal perforation, and wound infection. ${ }^{\mathrm{b}}$ More than 48 hours after surgery. 
system costs and postoperative morbidity. The risk for PONV is influenced by individual patient susceptibility, surgery, and anesthetic factors. Patients at risk for PONV include: females, those with history of PONV or motion sickness, use of postoperative opioids, nonsmokers, and those undergoing certain surgeries (gynecologic, neurologic, and intraabdominal).

In an effort to reduce PONV in these high risk groups, prophylactic antiemetic regimens have been evaluated. Commonly used agents include 5-HT3 antagonists, dexamethasone, droperidol, cyclizine, transdermal scopolamine, and metoclopramide. Numerous studies have demonstrated that combination therapy with drugs from different classes is more effective than single drug therapy.

Aprepitant is a first in class highly selective NK-1 receptor antagonist that can be administered orally (although an IV form also recently became available) preoperatively for PONV prophylaxis. Substance P is a neurokinin neurotransmitter that acts through the NK-1 receptor found in both peripheral and central nervous systems to induce nausea and vomiting. This class of drugs is widely used for CINV. Early evidence suggesting potential efficacy of the NK-1 receptor antagonists (using pilot drugs) as prophylaxis against PONV was noted in two studies of patients undergoing gynecologic surgery [14] [15]. Trials comparing the clinical utility of aprepitant versus ondansetron in open abdominal surgery also noted it to be an effective pharmacologic tool for the prevention of PONV [16]. Specifically, aprepitant was superior to ondansetron for prevention of vomiting at 24 and 48 hours post operatively, but similar to ondansetron in prevention of nausea control, use of rescue, or complete response (no vomiting and no rescue therapy).

Rather than comparing efficacies of ondansetron and aprepitant as in the previous phase III trial, we designed this study to reflect our need to improve upon PONV for a higher risk population of female patients undergoing hysterectomy by adding aprepitant to our standard inexpensive prophylactic measures of dexamethasone and ondansetron. A chart review of hysterectomies prior to this prospective study determined a baseline rate of emesis of approximately $20 \%$ in the first 24 hours postoperative, and increased to over $25 \%$ by 48 hours postoperative. Additionally, over half of our patients experienced difficulty with nausea postoperatively, leading to considerable use of rescue antiemetic therapies and a 5\% prolonged hospitalization/readmission rate.

Although our current trial's numbers failed to reach significance, there did appear to be a trend towards reduction of PONV in our study population. Three other studies from Korea and Japan [17]-[19] have had similar results in PONV prophylaxis using aprepitant preoperatively prior to gynecologic laparoscopy, but not specifically hysterectomy. These trials compared doses ranging from 80 - $125 \mathrm{mg}$ delivered orally 2 - 3 hours prior to surgery versus placebo. All three trials were able to demonstrate a statistically significant reduction in PONV both in the immediate $(0-2 \mathrm{~h})$ and delayed $(2-24 \mathrm{~h})$ postoperative periods. There was no clinical improvement based on the $80 \mathrm{mg}$ versus $125 \mathrm{mg}$ dose. Possible explanation as to why a statistically significant difference was observed in these studies and not in ours include: First, all 3 of these studies used a higher dose of aprepitant (80 $\mathrm{mg}$ ) compared to our trial $(40 \mathrm{mg})$. This higher dose may explain why the incidence of vomiting was remarkably lower $(0 \%-4 \%$ over $24 \mathrm{~h})$ in these trials' study groups compared to our study group (17\%). Second, in our study we administered ondansetron and dexamethasone preemptively in both the treatment and placebo groups, possibly blunting the impact of the study drug.

\section{Conclusion}

In conclusion, combination of antiemetic agents in the prophylaxis of PONV is the most effective strategy in highest risk patients. The preemptive use of NK-1 receptor antagonists may be valuable in the armamentarium of prophylactic antiemetics to decrease the incidence of PONV in patients as it is mechanistically different from other antiemetic agents. This study suggested a trend towards reduction of PONV in elective hysterectomy patients with the addition of a $40 \mathrm{mg}$ preoperative prophylactic dose of aprepitant. However, further studies are necessary to confirm these findings and identify the correct dosage for PONV in gynecologic surgery as our numbers were not able to reach statistical significance.

\section{References}

[1] Apfel, C.C., Leara, E., Koivuranta, M., et al. (1999) A Simplified Risk Score for Predicting Nausea and Vomiting: Conclusions and Cross-Validations between Two Centers. Anesthesiology, 91, 693-700. http://dx.doi.org/10.1097/00000542-199909000-00022

[2] Gan, T.J. (2006) Risk Factors for Postoperative Nausea and Vomiting. Anesthesia \& Analgesia, 102, 1884-1898. 
http://dx.doi.org/10.1213/01.ANE.0000219597.16143.4D

[3] Watcha, M.F. and White, P.F. (1992) Postoperative Nausea and Vomiting: Its Etiology, Treatment, and Prevention. Anesthesiology, 77, 162-168. http://dx.doi.org/10.1097/00000542-199207000-00023

[4] Flemm, L.A. (2004) Aprepitant for Chemotherapy-Induced Nausea and Vomiting. Journal of Clinical Oncology, 8, 303-306.

[5] de Wit, R., et al. (2004) The Oral NK-1 Antagonist, Aprepitant, Given with Standard Antiemetics Provides Protection Against Nausea and Vomiting over Several Cycles of Cisplatin-Based Chemotherapy. European Journal of Cancer, 40, 403-407. http://dx.doi.org/10.1016/j.ejca.2003.08.028

[6] Chawla, S.P., et al. (2003) Establishing the Dose of the Oral NK-1 Antagonist Aprepitant for the Prevention of Chemotherapy Induced Nausea and Vomiting. Cancer, 97, 2290-2300. http://dx.doi.org/10.1002/cncr.11320

[7] Stahl, S.M. (2003) The Ups and Downs of Novel Antiemetic Drugs. Journal of Clinical Psychiatry, 64, 498-499. http://dx.doi.org/10.4088/JCP.v64n0501

[8] Dando, T.M. and Perry, C.M. (2004) Aprepitant: A Review of Its Use in the Prevention of Chemotherapy-Induced Nausea and Vomiting. Drugs, 64, 777-794. http://dx.doi.org/10.2165/00003495-200464070-00013

[9] Navari, R.M. (2004) Aprepitant: A NK-1 Receptor Antagonist for Chemotherapy-Induced Nausea and Vomiting. Expert Review Anticancer Therapy, 4, 715-724. http://dx.doi.org/10.1586/14737140.4.5.715

[10] Jordan, K. (2006) Neurokinin-1-Receptor Anatagonists: A New Approach to Antiemetic Therapy. Onkologie, 29, 3943. http://dx.doi.org/10.1159/000089800

[11] Massaro, A.M. and Lenz, K.L. (2005) Aprepitant: A Novel NK-1 Receptor Antagonist for Chemotherapy-Induced Nausea and Vomiting. The Annals of Pharmacotherapy, 39, 77-85. http://dx.doi.org/10.1345/aph.1E242

[12] Patel, L. and Lindley, C. (2003) Aprepitant: A Novel NK-1 Receptor Anatgonist. Expert Opinion on Pharmacotherapy, 4, 2279-2296. http://dx.doi.org/10.1517/14656566.4.12.2279

[13] Merck \& Co., Inc. (2003) Emend: Highlights of Prescribing Information. http://www.merck.com/product/usa/pi_circulars/e/emend/emend_pi.pdf?WT.mc_id=N02N3

[14] Gesztesi, Z., Scuderi, P.E., White, P.F., et al. (2000) Substance P (Neurokinin-1) Antagonist Prevents Postoperative Vomiting after Abdominal Hysterectomy Procedures. Anesthesiology, 93, 931-937. http://dx.doi.org/10.1097/00000542-200010000-00009

[15] Diemunsch, P., Schoeffler, P., Bryssine, B., et al. (1999) Antiemetic Activity of the NK-1 Receptor Antagonist (GR205171) in the Treatment of Established Postoperative Nausea and Vomiting after Major Gynaecological Surgery. British Journal of Anaesthesia, 82, 274-276. http://dx.doi.org/10.1093/bja/82.2.274

[16] Gan, T.J., Apfel, C.C., Kovac, A., et al. (2007) A Randomized, Double-Blind Comparison of the NK1 Antagonist, Aprepitant, Versus Ondansetron for the Prevention of Postoperative Nausea and Vomiting. Anesthesia \& Analgesia, 104, 1082-1089. http://dx.doi.org/10.1213/01.ane.0000263277.35140.a3

[17] Kakuta, N., Tsutsumi, Y.M., Horikawa, Y.T., et al. (2011) Neurokini-1 Receptor Antagonism, Aprepitant, Effectively Diminishes Post-Operative Nausea and Vomiting While Increasing Analgesic Tolerance in Laparoscopic Gynecologic Procedures. The Journal of Medical Investigation, 58, 246-251. http://dx.doi.org/10.2152/jmi.58.246

[18] Jung, W.S., Kim, Y.B., Park, H.Y., et al. (2013) Oral Administration of Aprepitant to Prevent Postoperative Nausea in Highly Susceptible Patients after Gynecologic Laparoscopy. Journal of Anesthesia, 27, 396-401. http://dx.doi.org/10.1007/s00540-012-1529-9

[19] Lee, S.-J., Lee, S.M., Kim, S.I., et al. (2012) The Effect of Aprepitant for the Prevention of Postoperative Nausea and Vomiting in Patients Undergoing Gynecologic Surgery with Intravenous Patient Controlled Analgesia Using Fentanyl: Aprepitant plus Ramosetron vs. Ramosetron Alone. Korean Journal of Anesthesiology, 63, 221-226. http://dx.doi.org/10.4097/kjae.2012.63.3.221 
Scientific Research Publishing (SCIRP) is one of the largest Open Access journal publishers. It is currently publishing more than 200 open access, online, peer-reviewed journals covering a wide range of academic disciplines. SCIRP serves the worldwide academic communities and contributes to the progress and application of science with its publication.

Other selected journals from SCIRP are listed as below. Submit your manuscript to us via either submit@scirp.org or Online Submission Portal.
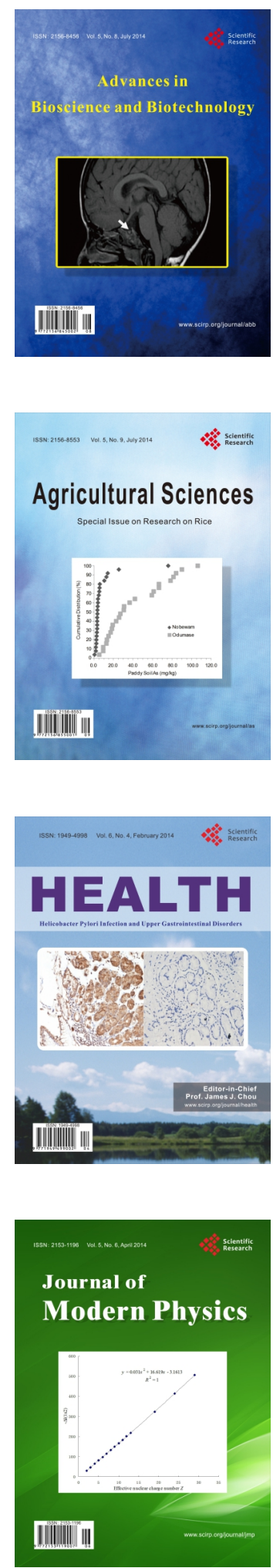
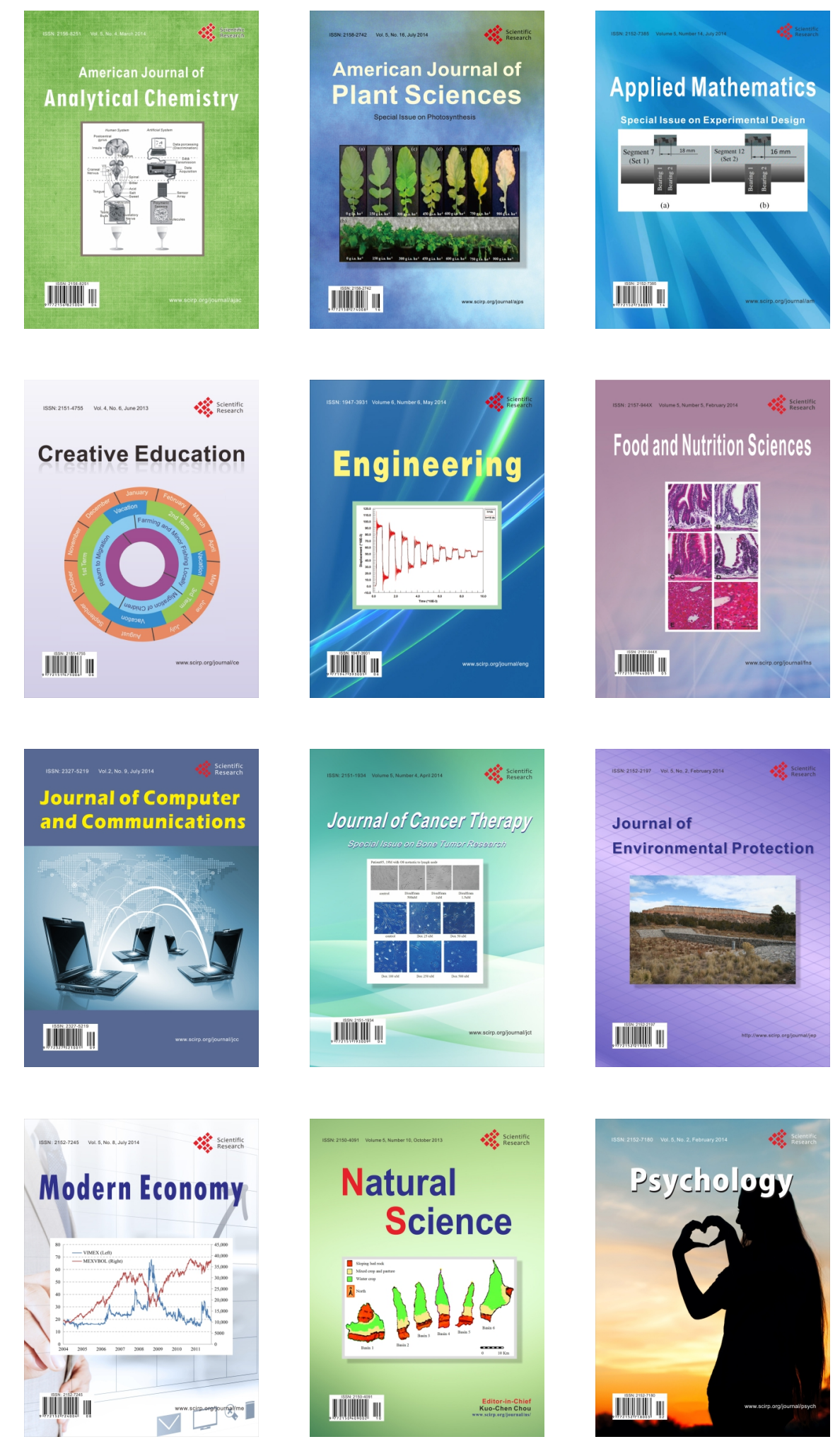